\title{
Could promontories have restricted sea-glacier penetration into marine embayments during Snowball Earth events?
}

\author{
Adam J. Campbell ${ }^{1, a}$, Betzalel Massarano ${ }^{1, b}$, Edwin D. Waddington ${ }^{1}$, and Stephen G. Warren ${ }^{1,2}$ \\ ${ }^{1}$ Department of Earth and Space Sciences, University of Washington, Seattle, Washington, USA \\ ${ }^{2}$ Astrobiology Program, University of Washington, Seattle, Washington, USA \\ ${ }^{a}$ now at: School of Surveying, University of Otago, Dunedin, New Zealand \\ ${ }^{b}$ now at: Pacific Science Center, Seattle, Washington, USA \\ Correspondence to: Adam J. Campbell (a.campbell@ otago.ac.nz)
}

Received: 24 August 2016 - Discussion started: 21 September 2016

Revised: 15 March 2017 - Accepted: 1 April 2017 - Published: 8 May 2017

\begin{abstract}
During the Neoproterozoic ( 1000-550 Ma), Earth experienced several climate excursions of extreme cold, often referred to as the Snowball Earth events. During these periods, thick flowing ice, referred to as sea glaciers, covered the entire planet's oceans. In addition, there is evidence that photosynthetic eukaryotic algae survived during these periods. With thick sea glaciers covering the oceans, it is uncertain where these organisms survived. One hypothesis is that these algae survived in marine embayments hydrologically connected to the global ocean, where the flow of sea glacier could be resisted. In order for an embayment to act as a refugium, the invading sea glacier must not completely penetrate the embayment. Recent studies have shown that straight-sided marine embayments could have prevented full sea-glacier penetration under a narrow range of climate conditions suitable for the Snowball Earth events. Here we test whether promontories, i.e., headlands emerging from a side shoreline, could further restrict sea-glacier flow. We use an ice-flow model, suitable for floating ice, to determine the flow of an invading sea glacier. We show that promontories can expand the range of climate conditions allowing refugia by resisting the flow of invading sea glaciers.
\end{abstract}

\section{Introduction}

During the Neoproterozoic, the entire upper ocean surface may have been covered by ice several hundreds of meters thick (Goodman and Pierrehumbert, 2003; Goodman, 2006; Li and Pierrehumbert, 2011). These periods of global ocean ice cover, commonly referred to as the Snowball Earth events, lasted multiple millions of years during at least two separate periods of the Neoproterozoic (Hoffman et al., 1998). Fossil evidence demonstrates that photosynthetic eukaryotic algae existed immediately prior to and after these events (Cohen et al., 2015; Knoll, 1992; Macdonald et al., 2010), implying they survived during the Snowball Earth events. Ice covering the ocean, thick enough to deform under its own weight as a "sea glacier", restricted the possible locations for survival of photosynthetic organisms. However, sea-glacier ice would have been too thick to allow for the transmission of light to the liquid water below the sea glacier, a necessary condition for photosynthesis, thereby setting up an apparent contradiction. It has been suggested that the evidence of survival of photosynthetic organisms during these times implies an incomplete cover of ice. Hoffman and Schrag (2000) suggested that small pools of open water could be maintained near volcanic islands, in order to reconcile the apparent contradiction; however this theory has not been rigorously explored. Warren et al. (2002) mentioned that marine embayments may have provide refugia for photosynthetic algae during the Snowball Earth events; as a sea glacier encountered a marine embayment, the sea-glacier invasion would be resisted by drag along the walls of the embayment. If such a marine embayment had appropriate geometry, the invading sea glacier might be unable to fully penetrate the embayment. The portion of the embayment not penetrated by the sea glacier might then be able to provide a refugium for photosynthetic organisms. In an exploration of this idea, Campbell et al. $(2011,2014)$ demonstrated that, 
under a range of climate conditions that could be expected during the Snowball Earth events, sea glaciers could have failed to completely penetrate narrow marine embayments hydraulically connected to the ocean, thereby satisfying a necessary condition for creating refugia for photosynthetic life.

Our previous studies considered the viability of marine embayments (referred, as inland seas in previous publications) to provide refugia for photosynthetic eukaryotes during the Snowball Earth events of the Neoproterozoic (Campbell et al., 2011, 2014). We found that straight-sided marine embayments limit sea-glacier penetration, and, in regions of net sublimation, an invading sea glacier could sublimate completely before reaching the end of the embayment, under a limited range of climate conditions. In Campbell et al. (2014), we considered ice flowing through a narrow entrance into a wider channel. Ice flowing through a narrow entrance moves parallel to the embayment axis. The ice then spreads out laterally into the regions immediately adjacent to the entrance (Campbell et al., 2014; Fig. 4). We found that under some combinations of entrance widths and climate conditions (i.e., temperature and sublimation rate), seaglacier-free regions could exist near the entrance of the channel. We suggested that a similar situation could exist behind an obstruction such as a promontory or island farther along the channel, creating a sea-glacier-free zone, which we call an ice shadow. Such a region might also be free of locallygrown sea ice (Fig. 1). We defined sea-glacier-free zones as regions where locally grown sea ice would be thin enough to allow for transmission of light. We found ice shadows could only exist near the entrance of the channel at very cold temperatures. In this study, we examine promontories along the channel sidewalls that are far from the entrance of the channel in order to capture both upstream and downstream effects of promontories and to determine if ice shadows can form downstream at warmer temperatures.

These ice shadows might have provided refugia for photosynthetic organisms in channels that would otherwise have been completely filled by sea glaciers. Channels containing several ice-free spots could be more robust at preserving organisms during the glaciation-deglaciation cycle of a Snowball Earth event.

Here we calculate the flow of floating ice around obstructions to address two questions: (1) how much does a promontory reduce sea-glacier penetration and (2) can promontories generate thin-ice zones on their leeward sides capable of independently acting as refugia?

In Sect. 2, we provide an explanation for why ice shadows exist and provide examples of ice shadows on the modern Earth. Section 3 describes the methods we use for ice-flow modeling and how we constrain appropriate climate conditions for our model. In Sect. 4 we describe the results of our experiments in term of metrics useful for exploring seaglacier penetration. In Sect. 5 we discuss our results including how promontories affect sea-glacier penetration, our un-

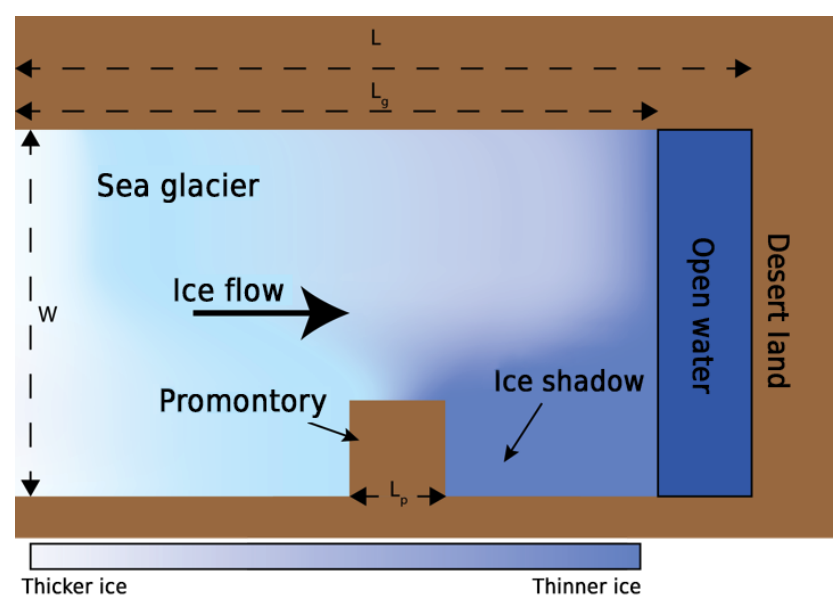

Figure 1. Cartoon illustration of ice shadow forming as sea glacier flows around a promontory in a channel. Note how ice thickens ahead of the promontory and thins behind the promontory.

derlying assumptions, and model limitations. Section 6 provides our conclusions.

\section{Modern ice shadows}

As floating ice approaches islands, promontories, or other obstructions, the ice slows down and tends to thicken relative to nearby unobstructed ice. The resulting surface gradients transverse to the flow axis, and interaction with sidewalls allows ice to flow around and away from the obstruction. When ice flowing down a channel encounters a constriction, ice must thicken and change its surface gradient to allow the same amount of ice to move through the smaller crosssectional area in the constricted region. Therefore, the average ice speed is greater through the constricted region. However, near the obstruction, lateral drag slows the ice relative to ice at a corresponding position upstream or downstream from the obstruction. Due to the high effective viscosity of ice, the fast-flowing ice moving through the constricted region then has difficulty changing direction and flowing toward the downstream side of the obstruction, creating a thin-ice zone, which we refer to as an ice shadow. In faster flow, the ice is swept farther past the promontory before it can spread significantly. A qualitative illustration of an ice shadow is shown in Fig. 1, and Sect. 4 includes model results.

Features similar to the ice shadows that we are hypothesizing can be seen on the modern Earth. In McMurdo Sound, Antarctica, the Ross Ice Shelf creates an ice shadow as it flows past White Island (Fig. 2a). On the opposite side of White Island, the ice is thinned sufficiently to allow a tidal crack to remain open continuously. In an interesting coincidence, this ice shadow is a refugium. A colony of Weddell seals remains isolated from other Weddell seal populations because an ice-shelf advance isolated White Island sometime 


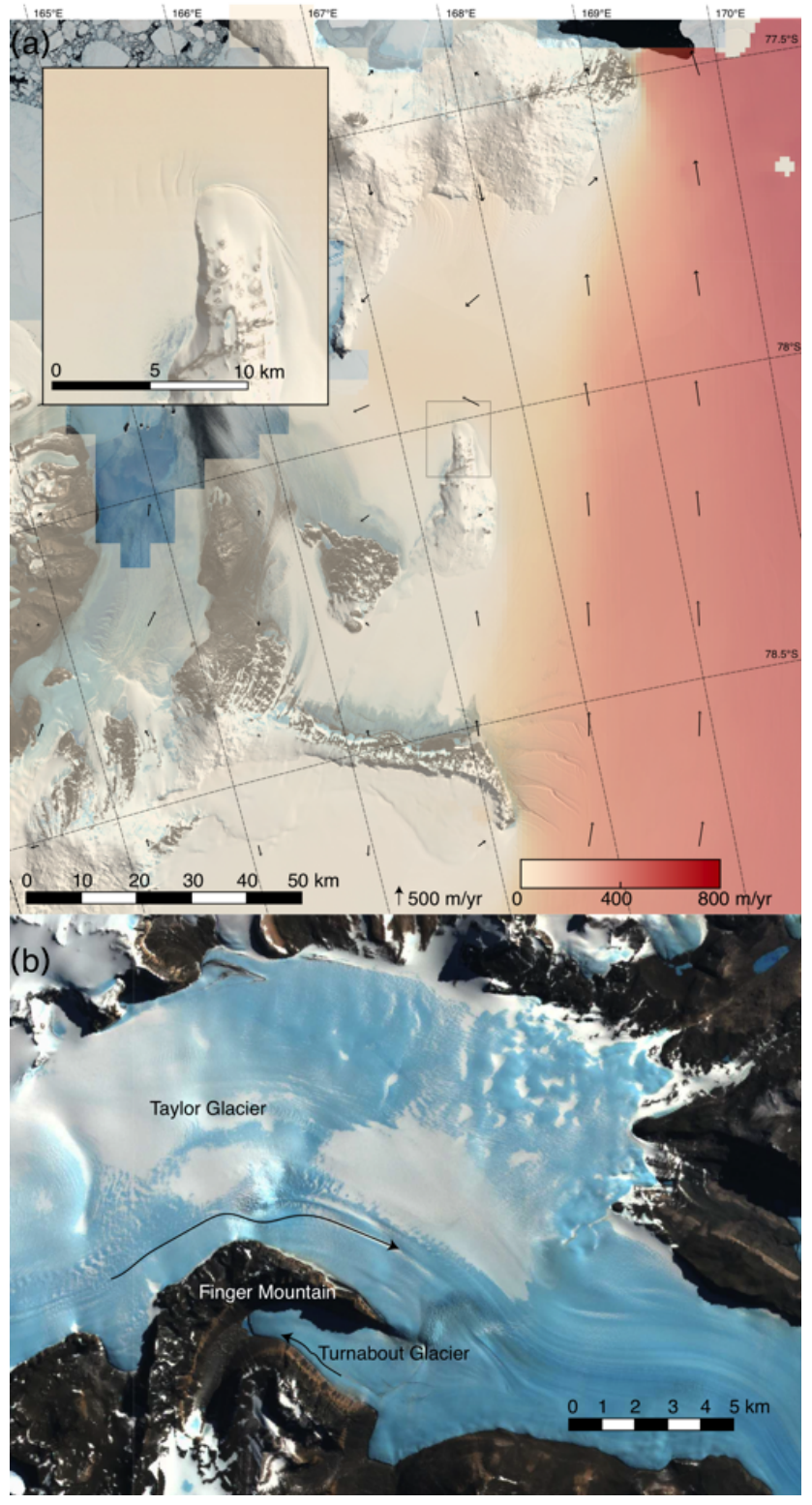

Figure 2. (a) Satellite image of Ross Ice Shelf flowing around White Island $\left(78.1^{\circ} \mathrm{S}, 167.4^{\circ} \mathrm{E}\right)$ forming an ice shadow on the northwest side of White Island where a tidal crack can form (inset); the color bar and arrow respectively indicate velocity direction and magnitude assembled from multiple satellite interferometric synthetic-aperture radar data acquired from 2007 to 2009 (Rignot et al., 2011). (b) The grounded Taylor Glacier flowing around Finger Mountain $\left(77.8^{\circ} \mathrm{S}, 161.3^{\circ} \mathrm{E}\right)$ and incompletely penetrating Turnabout Valley. Arrows trace representative flow lines and flow direction. Imagery from Landsat Image Mosaic Of Antarctica (LIMA).

between 1947 and 1956. The tidal crack remains their only point of access into the ocean (Gelatt et al., 2010).

An ice shadow in grounded ice can be seen in Taylor Valley in Antarctica (Fig. 2b), where a small distributary of Taylor Glacier flows around Finger Mountain in a 180-degree turn, becoming the much-thinner Turnabout Glacier, which then incompletely penetrates Turnabout Valley.

\section{Methods}

Here we explore how introducing a square promontory into a channel affects ice flow as compared to flow in a straightwalled channel without a promontory. In our experiments, we vary three parameters: the size of the square promontory, the surface air temperature, and the sublimation rate. Surface air temperature and sublimation rate are boundary conditions on the ice-flow model (described in Sect. 3.1). The ice-flow model can be used with any combination of surface air temperature and sublimation rate; however, since we are concerned with potential refugia for photosynthetic life, we choose to investigate primarily climate conditions that might suit the transmission of light through ice (see Sect. 3.2). These two requirements interact: warm surface temperature is needed to prevent thick ice growing locally, blocking light transmission, but warm temperature softens glacier ice, allowing it to flow more easily around the promontory where it could cover the potential refugium.

We performed a series of experiments to determine the amount of thinning as ice flows around a promontory. The geometry of our experiments consisted of an idealized rectangular channel with width $W$ and length $L$, here $W$ is $200 \mathrm{~km}$ and $L$ is long enough to prevent the sea glacier from contacting the end of the channel. A square promontory (Fig. 1), with side length $L_{\mathrm{p}}$, was placed along one sidewall. For most experiments, the promontory was centered at $x=0.85 L_{\mathrm{g}}$. We assumed that the promontory walls and the channel sidewalls were very steep and very high, and hence the sea glacier could not move onto the promontory; a low promontory that could be overridden by the sea glacier would require a different model. This approach is an idealization; if the sea glacier were allowed to move onto the promontory, it could increase or decrease sea-glacier penetration. We then numerically solved for sea-glacier thickness $h(x, y)$ and the velocity field $u(x, y)$, searching for an $L_{\mathrm{g}}$ such that the dynamic flow of ice into the channel was balanced by sublimation over the sea glacier. We performed this operation while varying promontory size $L_{\mathrm{p}}$ and combinations of surface temperature $T_{\mathrm{S}}$ and sublimation rate $\dot{b}$. The promontory side length $L_{\mathrm{p}}$ is varied from 0 (i.e., no promontory) to $100 \mathrm{~km}$. We used ten combinations of surface temperatures ranging from -5.7 to $-4.6^{\circ} \mathrm{C}$ and sublimation rates ranging from -2 to $-20 \mathrm{~mm}$ year $^{-1}$, which produced thin (see Sect. 3.2), locally grown sea ice with a thickness of $50 \mathrm{~m}$ (see Fig. 3).

\subsection{Sea-glacier flow model}

To simulate the behavior of a sea glacier flowing in a channel containing a promontory, we used an ice-flow model solving an approximation to the Stokes momentum-balance 
Table 1. Constants used in analysis.

\begin{tabular}{lrrr}
\hline Name & Symbol & Value & Units \\
\hline geothermal flux & $F_{\text {geo }}$ & 0.1 & $\mathrm{~W} \mathrm{~m}^{-2}$ \\
acceleration of gravity & $g$ & 9.81 & $\mathrm{~m} \mathrm{~s}^{-2}$ \\
thermal conductivity of ice & $k$ & 2.5 & $\mathrm{~W} \mathrm{~m}^{-1} \mathrm{~K}^{-1}$ \\
latent heat of fusion of ice & $L_{\mathrm{i}}$ & $3.3 \times 10^{5}$ & $\mathrm{~J} \mathrm{~kg}^{-1}$ \\
freezing temperature of sea water & $T_{\mathrm{f}}$ & -2 & ${ }^{\circ} \mathrm{C}$ \\
ice density & $\rho_{\mathrm{i}}$ & 917 & $\mathrm{~kg} \mathrm{~m}^{-3}$ \\
\hline
\end{tabular}

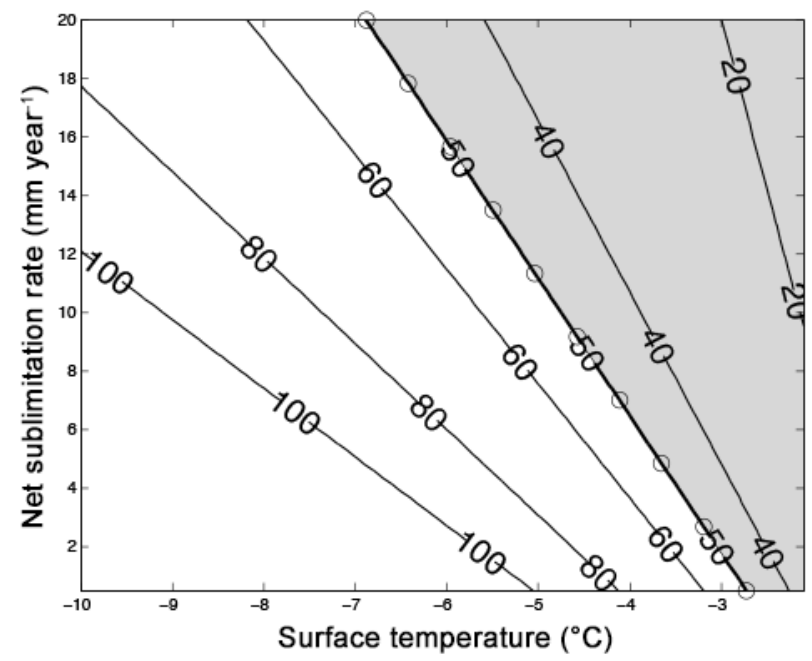

Figure 3. Ice-thickness contours (in meters) for combinations of surface temperature and sublimation rate as predicted by Eq. (1). Combinations of sublimation rate and surface temperature used in experiments are shown with hollow circles.

equations (called the shallow-shelf approximation, Morland, 1987; MacAyeal et al., 1996) in steady state. Here we outline the ice-flow modeling procedure; Campbell et al. (2014) provided more details. The Shallow Shelf Approximation is an approximation of the Stokes equations that is suitable for floating ice where the vertical dimension is much smaller than the horizontal dimensions. This model incorporates both lateral shearing and longitudinal stretching. We specify mean-annual surface temperature and sublimation rate, both spatially uniform and temporally constant. A Glen's flow law viscosity is used (Glen, 1955) with an ice-softness parameter based on the mean-annual surface temperature (Cuffey and Paterson, 2010, p. 75). Along the entrance of the channel, a constant-pressure boundary condition is applied, representing a uniform ice thickness along the boundary. Along the sidewalls and along the promontory, no-slip conditions are applied, a suitable condition for ice below the melting point. Along the terminus of the sea-glacier, an integrated hydrostatic equilibrium condition specifies pressure due to seawater. We chose not to model the effect of sea or mélange back pressure; however, doing so would reduce sea-glacier pen- etration. To determine penetration length $L_{\mathrm{g}}$, we iteratively changed the sea-glacier length until the dynamic ice flux entering the channel balanced the kinematic ice flux lost by sublimation integrated over the entire glacier surface area. These equations were solved using a commercially available finite-element solver, COMSOL Multiphysics ${ }^{\circledR}$ (https: //www.comsol.com/).

\subsection{Temperature and sublimation rate}

In this study, we search for combinations of surface temperature and sublimation rate that can maintain thin sea ice or open water. Sea ice thickness would be larger if the surface temperature was colder or if the sublimation rate was lower.

\section{Equilibrium sea-ice thickness}

Sublimation rate and surface temperature are related to equilibrium sea-ice thickness through a heat-conduction equation:

$h=\frac{k\left(T_{\mathrm{f}}-T_{\mathrm{s}}\right)}{\rho_{\mathrm{i}} L_{\mathrm{i}} \dot{b}+F_{\text {geo }}}$,

where $h$ represents the ice thickness, $k$ is the thermal conductivity, $T_{\mathrm{f}}$ is the freezing temperature in the ocean, $T_{\mathrm{S}}$ is the surface temperature, $\rho_{\mathrm{i}}$ is the density of sea ice, $L_{\mathrm{i}}$ is the heat of fusion of sea ice, $\dot{b}$ is the rate of sea-ice growth at the base (assumed equal to the net sublimation rate in steady state; thicker, flowing ice would not require a freeze-on mechanism to balance the surface sublimation), and $F_{\text {geo }}$ is the geothermal flux. The sublimation rate is linked to temperature by the Clausius-Clapeyron equation, as in Campbell et al. (2014). Equation (1) is a simplification of Eq. (1) of Warren et al. (2002), in which we have omitted the penetration of solar radiation. Equilibrium sea-ice thicknesses calculated using Eq. (1) are shown in Fig. 3. By choosing not to consider the effect of solar absorption within the ice, our calculations provide an upper bound on sea-ice thickness for a given $T_{\mathrm{S}}$ and $\dot{b}$. Values used to calculate $h$ in Fig. 3 are given in Table 1 . The albedo of ice can strongly affect sea-ice thickness, with bare ice likely absorbing enough light to remain thin enough to allow photosynthesis under the ice, although photosynthesis may be possible within brine pockets of otherwise thicker ice (Warren et al., 2002); however, a salt crust may develop 

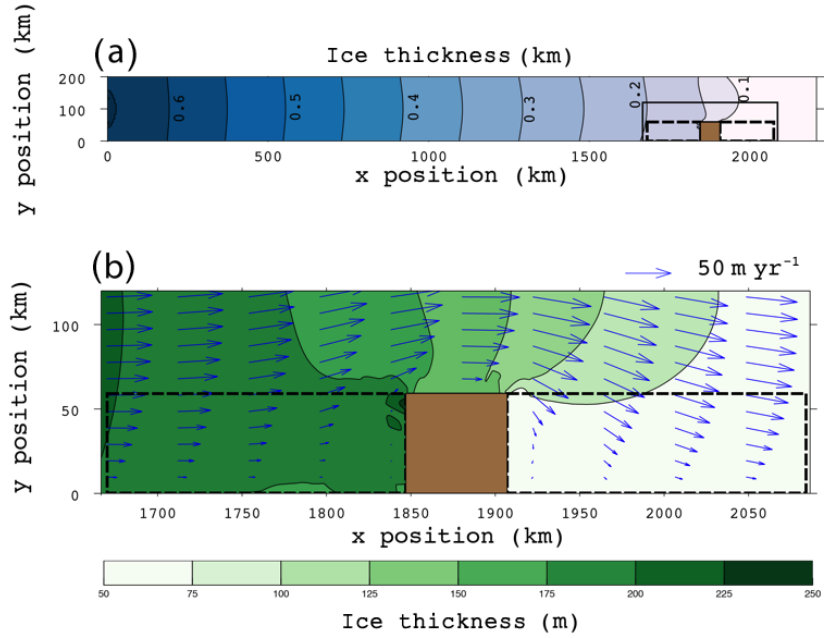

Figure 4. Results from a sample sea-glacier flow model where $T_{\mathrm{S}}=-5.33^{\circ} \mathrm{C}, \dot{b}=12.70 \mathrm{~mm} \mathrm{yr}^{-1}$, and $L_{\mathrm{p}}=60 \mathrm{~km}$. Arrows indicate flow speed and direction; a reference arrow for $50 \mathrm{~m} \mathrm{yr}^{-1}$ is shown. Contours show ice thickness. Dashed rectangles indicate upstream (left) and downstream (right) regions where ice thickness is evaluated. (a) The entire model domain, with a $50 \mathrm{~m}$ contour interval. (b) An enlarged section around the promontory, with a $25 \mathrm{~m}$ contour interval.

on sea ice, thereby increasing the sea-ice albedo (Light et al., 2009), increasing ice thickness, and possibly preventing photosynthesis under the ice surface.

\section{Results}

Far upstream of the promontory, ice flow is fastest along the center of the channel, and the pattern of ice flow is indistinguishable from ice in flow in an unobstructed channel (Fig. 4 for an representative case); however, the overall ice speed is slower in the obstructed case, making the channel look narrower far upstream. As ice approaches the promontory, it slows and dynamically thickens. The length scale for this longitudinal strain is $\sim L_{\mathrm{p}}$ (Kamb and Echelmeyer, 1986). Ice thickening and longitudinal strain are not prominent toward the center of the channel; therefore, ice in the center of the channel thickens only slightly upstream of the promontory. This thickness gradient between ice directly upstream of the promontory and ice near the channel center results in ice flow being directed, through a stress balance, toward the center of the channel; the location of fastest flow here is displaced toward the sidewall opposite the promontory. As the ice moves beyond the promontory, it spreads laterally, driven by a thickness gradient between the center of the channel and the region immediately downstream of the promontory where the ice is thin; here the location of fastest flow returns toward a more central position. Far downstream of the promontory, the pattern of ice flow is indistinguishable from the pattern in an unobstructed channel; however, the overall ice speed is slower in the obstructed case. Ice flow is again fastest in the center of the channel.

We use two metrics to quantify the presence of ice shadows. These are thickness drop $\Delta H$ and thin-ice percentage (TIP). Thickness drop $\Delta H \equiv \overline{H_{\mathrm{U}}}-\overline{H_{\mathrm{D}}}$, where $\overline{H_{\mathrm{U}}}$ and $\overline{H_{\mathrm{D}}}$ represent mean ice thickness in regions directly upstream and downstream of the promontory respectively. Those upstream and downstream evaluation regions are chosen to have length $3 L_{\mathrm{p}}$ and width $L_{\mathrm{p}}$ (see dashed lines in Fig. 4). Scaling the evaluation regions with the size of the promontory allows the thickness drop to be more completely captured than if we were to use evaluation regions of constant size independent of $L_{\mathrm{p}}$, because we expect that the spatial extent of the disturbance should scale with $L_{\mathrm{p}}$. Thin-ice percentage is defined as the percentage of the downstream evaluation region where ice thickness falls below a specified value $H_{\text {thin }}$.

Thickness drop, $\Delta H$, increases with increasing promontory size $L_{\mathrm{p}}$ as seen in Fig. 5a, where $\Delta H$ is averaged over each of the $10 T_{\mathrm{s}}$ and $\dot{b}$ combinations for each $L_{\mathrm{p}}$ (Sect. 3). A penetration percentage can be calculated by dividing the penetration distance of a sea glacier into a channel with a promontory by the penetration distance in a control run in which a sea glacier flows into a channel without a promontory, for the same climate variables $T_{\mathrm{s}}$ and $\dot{b}$. Figure 5 a shows the mean value of the penetration percentage, calculated for each of the $10 T_{\mathrm{s}}$ and $\dot{b}$ combinations for each $L_{\mathrm{p}}$.

Our results reveal a similar correspondence between larger promontory sizes and higher downstream thin-ice percentages (Fig. 5b). For promontories with $L_{\mathrm{p}}$ of $10-30 \mathrm{~km}$, centered at $0.85 L_{\mathrm{g}}$, where $L_{\mathrm{g}}$ is the penetration distance in the control run, typically $25 \%$ of the ice in the downstream evaluation region is less than $75 \mathrm{~m}$ thick. For promontories with $L_{\mathrm{p}}$ of $10-50 \mathrm{~km}$, typically $1 \%$ is less than $50 \mathrm{~m}$ thick. For larger promontories, TIP increases such that $94 \%$ of the ice in the downstream evaluation region is less than $75 \mathrm{~m}$ thick, and typically $34 \%$ is less than $50 \mathrm{~m}$ thick.

\section{Discussion}

Figure 5a (blue curve) demonstrates a reduction in penetration percent as $L_{\mathrm{p}}$ increases. This result is physically sensible because the promontory partially blocks the channel. Increasing $L_{\mathrm{p}}$ increases the perimeter of the channel and therefore the overall drag experienced by the sea glacier. This result suggests that the choice of rectangular channels in Campbell et al. (2014) represents an upper bound for sea-glacier penetration into channels, because inclusion of promontories or islands would have reduced sea-glacier penetration, consistent with the continental constriction experiments of Tziperman et al. (2012).

An interesting result of this study is that we can calculate a "promontory efficiency". Smaller promontories are more efficient at increasing thickness drop and reducing overall seaglacier penetration per sidewall unit length (Fig. 5c). While 

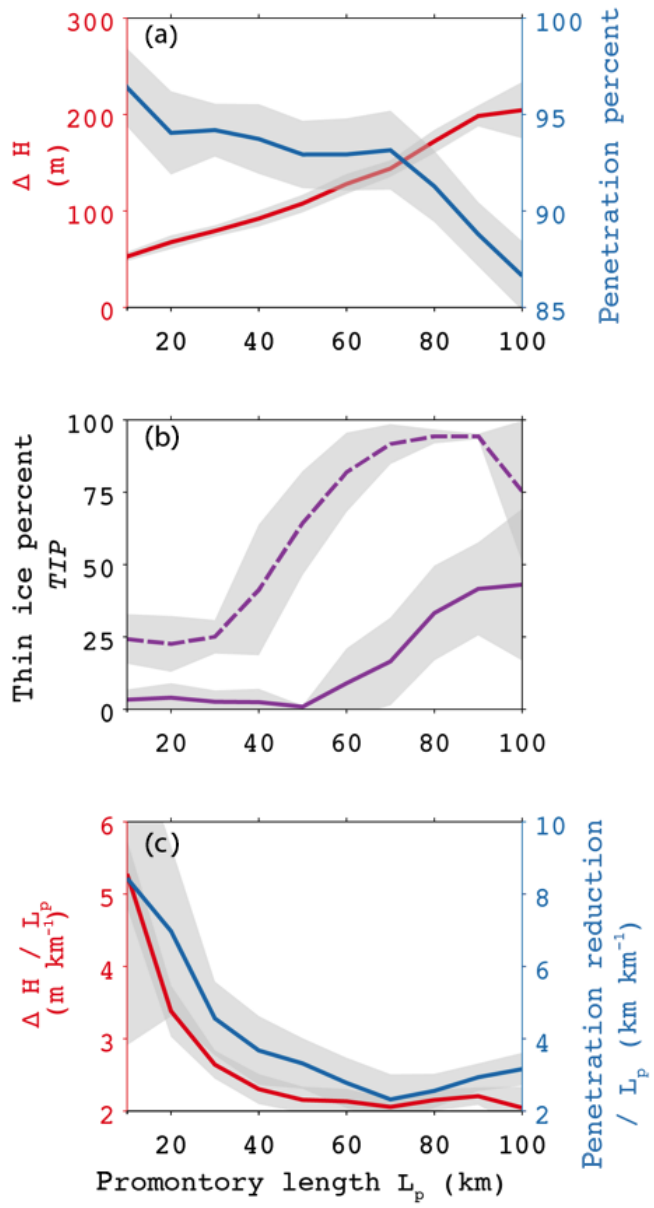

Figure 5. (a) Thickness drop $\Delta H$ (red) and penetration percent (blue) compared to a control run in a channel with no promontory. (b) Thin ice percentage for $H_{\text {thin }}=50 \mathrm{~m}$ (solid curve) and for $H_{\text {thin }}=75 \mathrm{~m}$ (dashed curve). (c) Thickness drop $\Delta H$ and penetration percent scaled by promontory length $L_{\mathrm{p}}$. For these experiments the channel width $W$ is $200 \mathrm{~km}$. Values are averaged over all $T_{\mathrm{S}}$ and $\dot{b}$ combinations for each promontory length $L_{\mathrm{p}}$. Gray regions include one standard deviation among $10 T_{\mathrm{S}}$ and $\dot{b}$ combinations (Sect. 3).

a single small promontory is relatively ineffective at generating a significant thickness drop or reduction in sea-glacier penetration, it is possible that an array of small promontories could be more effective than a single, larger promontory. At sufficiently close spacing, however, the promontories would interact with their neighbors, reducing this effect. Furthermore, there is likely some limit to this effect at sufficiently small promontory sizes. This further illuminates the concept that a straight-walled channel provides an upper bound on sea-glacier penetration.

Our experiments used square promontories. By generalizing this procedure to incorporate rectangular geometries, it would be possible to parse out the relative importance of

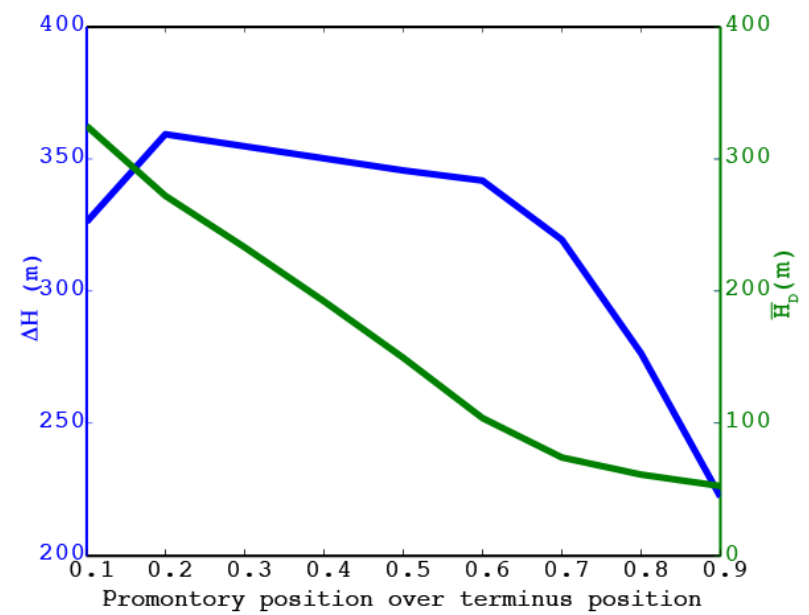

Figure 6. Thickness drop $\Delta H$ and mean down-stream thickness $\overline{H_{\mathrm{D}}}$ versus center of promontory position $X_{\mathrm{p}} / L$ along sidewall, expressed as a fraction of the glacier's total penetration length. Seaglacier terminus is to the right.

length along the channel or width across the channel at reducing sea-glacier penetration.

For our experiment, we also tested the model for sensitivity to promontory position by varying the location $X_{\mathrm{p}}$ of the center of the promontory from 0.1 to $0.9 L$, where $L$ is the total length of the glacier; Fig. 6 shows that the thickness drop $\Delta H$ remains roughly constant (at $\sim 340 \mathrm{~m}$ ) in the range of 0.1 to $0.7 L$ and falls off sharply (from $\sim 340$ to $\sim 270 \mathrm{~m}$ ) in the range of 0.7 to $0.9 \mathrm{~L}$. Despite the more significant thickness drop in the $0.1-0.7 L$ range of positions, we chose a promontory location of $0.85 \mathrm{~L}$ in order to increase the likelihood that ice downstream in the shadow could thin sufficiently to allow light to pass through.

It is possible that the surface of an invading sea glacier would be higher than the surface of a promontory. We assumed that the promontory walls and the channel sidewalls were steep and high, so that the sea glacier could not move onto the promontory. If the sea glacier were allowed to flow onto a shallow promontory, it might override the promontory, eliminating an ice shadow. However, a grounded sea glacier flowing over a promontory would still tend to slow because of the additional basal resistance, and the penetration length $L$ would be decreased, increasing the probability of a refugium farther along the channel. To model this effect would require a model capable of capturing basal resistance, which would be more complex than the model used here.

In order to ensure numerical stability of our model, we enforced a minimum ice thickness of $50 \mathrm{~m}$. However, this is a large value compared to the thickness of ice through which light will transmit (between 1-10 m, Warren et al., 2002) and, therefore, photosynthetic life could survive. If the minimum 
ice thickness could be reduced, then we would be able to better quantify the areal extent of zones with light transmission.

\section{Conclusions}

In this study we were interested in understanding the effect that promontories in channels could play in controlling the suitability of these channels as refugia for photosynthetic life during the Snowball Earth events. We calculated the flow of floating ice around promontories for conditions suitable during a Snowball Earth event. We have two major conclusions:

1. Ice shadows form behind promontories in channels, and these shadows could possibly provide refugia under the right circumstances. Ice flowing around a promontory is thinner downstream of the promontory relative to ice in a channel without a promontory; however, due to the resolution of our model, we were unable to quantitatively demonstrate if or when ice downstream of a promontory could be thin enough to provide a refugium in the ice shadow. For suitable conditions during the Snowball Earth events, sea-glacier ice could have thinned sufficiently on the downstream sides of large promontories in marine embayments to allow for photosynthesis.

2. The effect of including promontories along the shoreline of a channel reduces the invading sea glacier's total penetration, therefore potentially allowing a refugium to exist at the downstream end of the channel, over a larger range of climate conditions.

Data availability. Data from Rignot et al. (2011) were used in the construction of Fig. 2 and are publicly available at https://nsidc.org/ data/docs/measures/nsidc0484_rignot/.

Competing interests. The authors declare that they have no conflict of interest.

Acknowledgements. This research was supported by NSF grant ANT-11-42963.

Edited by: G. H. Gudmundsson

Reviewed by: S. L. Cornford and one anonymous referee

\section{References}

Campbell, A. J., Waddington, E. D., and Warren, S. G.: Refugium for surface life on Snowball Earth in a nearly-enclosed sea? A first simple model for sea-glacier invasion, Geophys. Res. Lett., 38, 1-5, doi:10.1029/2011GL048846, 2011.
Campbell, A. J., Waddington, E. D., and Warren, S. G.: Refugium for surface life on Snowball Earth in a nearly enclosed sea? A numerical solution for sea-glacier invasion through a narrow strait, J. Geophys. Res.-Oceans, 119, 2679-2690, doi:10.1002/2013JC009703, 2014.

Cohen, P. A., Macdonald, F. A., Pruss, S., Matys, E., and Bosak, T.: Fossils of putative marine algae from the Cryogenian glacial interlude of Mongolia, Palaios, 30, 238-247, 2015.

Cuffey, K. M. and Paterson, W. S. B.: The Physics of Glaciers, 4th edn., Elsevier, Amsterdam, 2010.

Gelatt, T. S., Davis, C. S., Stirling, I., Siniff, D. B., Strobeck, C., and Delisle, I.: History and fate of a small isolated population of Weddell seals at White Island, Antarctica, Conserv. Genet., 11, 721-735, doi:10.1007/s10592-009-9856-6, 2010.

Glen, J. W.: The Creep of Polycrystalline Ice, Proc. R. Soc. A Math. Phys. Eng. Sci., 228, 519-538, doi:10.1098/rspa.1955.0066, 1955.

Goodman, J. C.: Through thick and thin: Marine and meteoric ice in a "Snowball Earth" climate, Geophys. Res. Lett., 33, 2-5, doi:10.1029/2006GL026840, 2006.

Goodman, J. C. and Pierrehumbert, R. T.: Glacial flow of floating marine ice in "Snowball Earth", J. Geophys. Res., 108, 3308, doi:10.1029/2002JC001471, 2003.

Hoffman, P. F. and Schrag, D. P.: Snowball Earth, Sci. Am., 282, 68-75, 2000.

Hoffman, P. F., Kaufman, A. J., Halverson, G. P., and Schrag, D. P.: A Neoproterozoic Snowball Earth, Science, 281, 1342-1346, doi:10.1126/science.281.5381.1342, 1998.

Kamb, B. and Echelmeyer, K. A.: Stress-gradient coupling in glacier flow: I. longitudinal averaging of the influence of ice thickness and surface slope, J. Glaciol., 32, 268-284, 1986.

Knoll, A.: The early evolution of eukaryotes: a geological perspective, Science, 256, 622-627, doi:10.1126/science.1585174, 1992.

Li, D. and Pierrehumbert, R. T.: Sea glacier flow and dust transport on Snowball Earth, Geophys. Res. Lett., 38, 1-4, doi:10.1029/2011GL048991, 2011.

Light, B., Brandt, R. E., and Warren, S. G.: Hydrohalite in cold sea ice: Laboratory observations of single crystals, surface accumulations, and migration rates under a temperature gradient, with application to "Snowball Earth" J. Geophys. Res., 114, C07018, doi:10.1029/2008JC005211, 2009.

MacAyeal, D. R., Rommelaraere, V., Huybrechts, P., Hulbe, C. L., Determann, J., and Ritz, C.: An ice-shelf model test based on the Ross Ice Shelf, Antarctica, Ann. Glaciol., 23, 46-51, 1996.

Macdonald, F. A., Schmitz, M. D., Crowley, J. L., Roots, C. F., Jones, D. S., Maloof, A. C., Strauss, J. V., Cohen, P. A., Johnston, D. T., and Schrag, D. P.: Calibrating the Cryogenian, Science, 327, 1241-1243, doi:10.1126/science.1183325, 2010.

Morland, L. W.: Unconfined ice-shelf flow, in: Dynamics of the West Antarctic Ice Sheet, edited by: van der Veen, C. J. and Oerlemans, J., 99-116, Dordrecht, Kluwer Academic Publishers, 1987.

Rignot, E., Mouginot, J., and Scheuchl, B.: MEaSUREs InSARBased Antarctica Velocity Map, Boulder, Colorado USA: NASA EOSDIS Distributed Active Archive Center at NSIDC, http:// nsidc.org/data/docs/measures/nsidc0484_rignot/index.html (last access: 4 September 2012), 2011. 
Tziperman, E., Abbot, D. S., Ashkenazy, Y., Gildor, H., Pollard, D., Schoof, C. G., and Schrag, D. P.: Continental constriction and oceanic ice-cover thickness in a Snowball-Earth scenario, J. Geophys. Res., 117, C05016, doi:10.1029/2011JC007730, 2012.
Warren, S. G., Brandt, R. E., Grenfell, T. C., and McKay, C. P.: Snowball Earth: Ice thickness on the tropical ocean, J. Geophys. Res., 107, 3167, doi:10.1029/2001JC001123, 2002. 